\title{
Complementary foods consumed by 6-12-month-old rural infants in South Africa are inadequate in micronutrients
}

\author{
Mieke Faber* \\ Nutritional Intervention Research Unit, Medical Research Council, PO Box 19070, Tygerberg 7505, South Africa
}

Submitted 14 June 2004: Accepted 6 October 2004

\begin{abstract}
Objective: To determine the nutrient composition of complementary foods consumed by 6-12-month-old South African infants.

Design: Nutrient intake was determined for infants who were recruited to participate in a randomised controlled trial using a single 24-hour dietary recall.

Setting/subjects: Infants aged $6-12$ months $(n=475)$ residing in The Valley of a Thousand Hills, a rural area in KwaZulu-Natal, South Africa.

Results: Energy and protein intakes from complementary foods were adequate. Infants who consumed infant products (commercially available fortified infant cereals/ready-to-eat canned baby foods/formula milk powder) had significantly higher intakes of calcium, iron, zinc, vitamin A, thiamine, riboflavin, niacin, vitamin $\mathrm{B}_{6}$, vitamin $\mathrm{B}_{12}$ and vitamin $\mathrm{C}$ than infants who did not consume any infant products. For infants who consumed infant cereals $(n=142)$, these cereals provided $51 \%$ of total iron intake. Infant cereals provided more than $25 \%$ of total intake for magnesium, thiamine, niacin and vitamin $\mathrm{B}_{12}$. For infants consuming ready-to-eat canned baby foods $(n=77)$, these products contributed less than $15 \%$ of total intake for all the micronutrients. The nutrient density of the complementary diet was less than half the desired density for calcium, iron and zinc. Animal products were consumed by $17 \%$ of infants, $26 \%$ consumed dairy products and $18 \%$ consumed vitamin-A-rich fruit and vegetables during the 24-hour recall period.

Conclusion: The nutrient composition of complementary foods among rural South African infants was inadequate, especially for iron, zinc and calcium. Strategies should be developed to improve the nutritional quality of their diets.
\end{abstract}

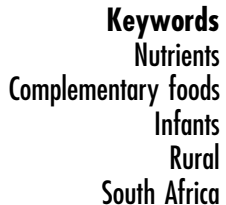

Inappropriate feeding practices is the major contributing factor to the high morbidity among infants and young children in developing countries ${ }^{1}$. Each year more than 10 million infants and young children die in developing countries before the age of 5 years ${ }^{2}$. Approximately half of these deaths are associated with malnutrition ${ }^{3}$, and more than two-thirds occur during the first year of life $e^{4}$. A national survey of 6-71-month-old children showed that in South Africa, children in the 6-23-month-old age group are the most vulnerable in terms of malnutrition 5 .

Because infants have high nutritional requirements relative to body size and consume small amounts of food, they require nutrient-dense foods. Complementary foods given in many developing countries are nutritionally inadequate $^{6}$. Porridge made with maize meal, which is a bulky food low in nutrient density, is used as complementary food in many African countries ${ }^{7-9}$, including South Africa ${ }^{10}$. Although fortification of maize meal became mandatory in South Africa in 2003, the impact thereof on infant nutrition will probably be minimal because of the small amount of maize meal that infants consume.
In the developed world, the baby food industry plays an important role in meeting the nutritional requirements of infants. For example, commercial baby foods feature prominently in the diets of American infants, which are generally nutritionally adequate ${ }^{11-13}$. However, inadequate dietary iron intakes were observed in South African infants in an urban area where most of the infants $(>80 \%)$ consumed fortified infant cereals. Dietary information showed that these fortified products were used in diluted form ${ }^{14}$. The intake of inadequate quantities of infant cereals was also shown for rural South African infants, and it was argued that the high cost of these products prohibited an adequate intake ${ }^{15}$.

The Nutritional Intervention Research Unit of the South African Medical Research Council evaluated the effect of a low-cost fortified baby porridge on the nutritional status of infants in The Valley of a Thousand Hills, a rural area of low socio-economic status. This provided the opportunity to determine feeding practices of these rural infants, and more specifically to evaluate the nutritional composition of the complementary diet. Data presented in this paper are the baseline data of the intervention study. 


\section{Participants and methods}

\section{Study area}

The study was done in the Valley of a Thousand Hills in KwaZulu-Natal Province, South Africa. This is a rural area with an estimated population of 200000 people. The population density is low as households are scattered over a large mountainous area. The community is predominantly Zulu-speaking. A recent study in the area showed that, of 6-12-month-old infants, $40 \%$ were anaemic (haemoglobin $(\mathrm{Hb})<11 \mathrm{~g} \mathrm{dl}^{-1}$ ), 18\% were vitamin-Adeficient (serum retinol $<20 \mu \mathrm{g} \mathrm{dl}^{-1}$ ) and $46 \%$ were zincdeficient (serum zinc $\left.<70 \mu \mathrm{g} \mathrm{dl}^{-1}\right)^{16}$.

The Valley Trust, one of South Africa's oldest and bestknown non-governmental organisations, runs an extensive community health worker programme in the area, with the aim to empower and encourage needy communities to accept greater responsibility for their own health. The area is better developed than many other rural areas in South Africa, reflecting The Valley Trust's involvement. For the infants participating in this study, 95\% of the households had access to tap water, $89 \%$ had access to toilet facilities and electricity was available in $78 \%$ of the households. Approximately one-third of the households had a home-garden, which was mostly for daily food needs. Eighty-three per cent of the infants' mothers were not married; $16 \%$ of the mothers were 18 years or younger at the time of the survey ${ }^{17}$.

\section{Study design}

Data were collected through a cross-sectional survey. All 6-12-month-old infants in the catchment area of eight community health centres were recruited through the community health worker programme of The Valley Trust. This study was part of the baseline survey of a randomised controlled trial ${ }^{17}$. Data on dietary intake were available for 475 of the 563 infants who were recruited; for the remaining 88 infants the caregivers could not provide reliable information as the infants were not permanently in their care.

\section{Data collection}

The mothers or caretakers (a member of the family, usually the grandmother of the child, in whose care the child was during the day), collectively referred to as caregivers, were interviewed in the local language (Zulu) by experienced fieldworkers.

Dietary intakes were quantified using a single 24-hour dietary recall. The interviews were done from Monday to Friday. The period covered by the 24-hour dietary recall therefore included one weekend and four weekdays (Sunday-Thursday). Fresh food, plastic food models, household utensils and three-dimensional sponge models were used to quantify and record food consumption for the previous day. In addition, dry oats was used to quantify portion sizes of certain food items, especially cooked food. The caregiver used the dry oats to indicate the quantity resembling the amount of food the infant consumed, which the fieldworker then quantified using a measuring cup. Food intake reported in household measures was converted into weight using the MRC Food Quantities Manual $^{18}$. For breast-feeding infants aged 6 to $<9$ months, a daily intake of $675 \mathrm{ml}$ breast milk was assumed ${ }^{19}$; for infants who consumed both breast milk and formula milk, the volume of the formula milk was subtracted from $675 \mathrm{ml}$ to obtain an estimate for the quantity of breast milk consumed. For breast-feeding infants aged 9 to $<12$ months, a daily intake of $615 \mathrm{ml}$ breast milk was assumed ${ }^{19}$; for infants who consumed both breast milk and formula milk, the volume of the formula milk was subtracted from $615 \mathrm{ml}$ to obtain an estimate for the quantity of breast milk consumed. The SAS software package (version 8.2; SAS Institute Inc., Cary, NC, USA) was used to convert food intake to macro- and micronutrients, using the MRC Food Composition Tables ${ }^{20}$ as food database.

The Dietary Reference Intakes published by the Institute of Medicine were used to assess nutritional adequacy ${ }^{21-26}$. For infants, requirements for most of the nutrients are expressed in terms of an Adequate Intake (AI). For iron and zinc an Estimated Average Requirement (EAR) is given. Dietary intake for the group is considered nutritionally adequate if the median intake for the group is at or above the AI. The EAR is used to estimate the prevalence of inadequate intakes within a group. The proportion of infants consuming less than the EAR for iron and zinc was not calculated, as at least two days of dietary recording are needed ${ }^{27}$.

Nutrient intakes of infants consuming infant products (ready-to-eat canned baby foods, infant cereals and formula milk powder) were calculated and compared with those of infants who did not consume any infant products. The difference in nutrient intakes between the two groups was determined using the Wilcoxon twosample test. $P$-values $<0.05$ were considered statistically significant. Protein and micronutrient densities per $100 \mathrm{kcal}$ of complementary foods alone for infants who received breast milk but no other milk feeds were calculated for two age categories $(6-<9$ months and $9-<12$ months) and compared with estimated desired nutrient densities.

\section{Ethical considerations}

This study was part of the baseline survey of a randomised controlled trial $^{17}$ that was approved by the Ethics Committee of the Medical Research Council. Each mother signed a consent form after the purpose and nature of the study had been explained to her.

\section{Results}

All of the infants were eating solid foods at the time of the survey. In addition, 58\% of the infants received breast milk 
alone, 18\% received bottle feeds alone, 23\% received mixed feeding (breast milk and bottle feeds) and 1\% did not receive any milk feeds.

\section{Total macro- and micronutrient intakes}

Energy, macro- and micronutrient intakes as determined by the 24-hour dietary recall are given in Table 1 . The median intakes for calcium, magnesium, vitamin $\mathrm{A}$, thiamine, riboflavin, vitamin $\mathrm{B}_{6}$ and vitamin $\mathrm{B}_{12}$ were all at or above the AI for 6-12-month-old infants. The median intakes for niacin, folic acid and vitamin $\mathrm{C}$ were below the AI. The median iron intake was $2.9 \mathrm{mg}$, versus the EAR of $6.9 \mathrm{mg}$.

\section{Nutrient contribution of infant products}

Infants who consumed infant cereals, ready-to-eat canned baby foods and/or formula milk powder during the 24-hour recall period were identified. Median nutrient intakes from infant products (given as the actual value, as well as the proportion of total intake) of those infants reported to consume (1) infant cereals, (2) ready-to-eat canned baby foods and (3) infant cereals and/or ready-toeat canned baby foods and/or formula milk powder (collectively referred to as infant products) are given in Table 2. For infants consuming infant cereals, these cereals provided $51 \%$ of total iron intake. Furthermore, infant cereals provided more than $25 \%$ of total intake for magnesium, thiamine, niacin and vitamin $\mathrm{B}_{12}$. For infants consuming ready-to-eat canned baby foods, these products contributed less than $15 \%$ of total intake for all the micronutrients.

Nutrient intakes of infants consuming infant products were compared with those of infants who did not

Table 1 Energy, macro- and micronutrient intakes of 6-12month-old infants as determined by a single 24 -hour dietary recall

\begin{tabular}{lcc}
\hline & Adequate Intake & $\begin{array}{c}\text { Dietary intake } \\
(n=475)\end{array}$ \\
\hline Energy $(\mathrm{kJ})$ & $\begin{array}{c}3121 \text { (boys) } \dagger \\
2839 \text { (girls) } \dagger\end{array}$ & $3470(3031,4013)$ \\
Protein $(\mathrm{g})$ & 13.5 & $17(13,23)$ \\
Total fat $(\mathrm{g})$ & 30 & $38(34,44)$ \\
Carbohydrates $(\mathrm{g})$ & 95 & $104(88,126)$ \\
Calcium $(\mathrm{mg})$ & 270 & $337(252,477)$ \\
Iron $(\mathrm{mg})$ & $6.9 \ddagger$ & $2.9(1.2,6.6)$ \\
Magnesium $(\mathrm{mg})$ & 75 & $80(58,111)$ \\
Zinc $(\mathrm{mg})$ & $2.5 \ddagger$ & $2.5(1.9,3.7)$ \\
Vitamin A $(\mu \mathrm{g} \mathrm{RE})$ & 500 & $524(458,719)$ \\
Thiamine $(\mathrm{mg})$ & 0.3 & $0.39(0.27,0.52)$ \\
Riboflavin $(\mathrm{mg})$ & 0.4 & $0.55(0.37,0.97)$ \\
Niacin $(\mathrm{mg})$ & 4 & $3.6(2.5,5.0)$ \\
Vitamin $\mathrm{B}_{6}(\mathrm{mg})$ & 0.3 & $0.37(0.23,0.58)$ \\
Vitamin $\mathrm{B}_{12}(\mu \mathrm{g})$ & 0.5 & $0.5(0,1.2)$ \\
Folic acid $(\mu \mathrm{g})$ & 80 & $72(50,111)$ \\
Vitamin C $(\mathrm{mg})$ & 50 & $46(36,72)$ \\
\hline
\end{tabular}

$\mathrm{RE}$ - retinol equivalents.

Values are given as the median and interquartile range (Q1, Q3).

* Adequate Intake of the US Dietary Reference Intake (DRI) published by the Institute of Medicine.

† Estimated energy requirement of the US DRI published by the Institute of Medicine.

$\ddagger$ Estimated Average Requirement of the US DRI published by the Institute of Medicine. consume any infant products. Significant differences in nutrient intakes were observed between the two groups. However, the age of the infants differed significantly between the two groups; infants who did not consume infant products were older than those who did consume infant products $(9.3 \pm 2.0$ months vs. $8.7 \pm 2.0$ months; $P=0.008)$. The infants were therefore grouped into two age categories, namely $6-<9$ months and $9-<12$ months. In both age categories, infants who consumed infant products had significantly higher intakes of calcium, iron, zinc, vitamin A, thiamine, riboflavin, niacin, vitamin $\mathrm{B}_{6}$, vitamin $\mathrm{B}_{12}$ and vitamin $\mathrm{C}$ than those infants who did not consume infant products (Table 3 ).

\section{Energy and nutrient requirements from complementary foods}

Complementary foods are defined as food-based sources of nutrients other than breast milk that are provided to infants who are still breast-feeding. Energy, protein and micronutrients from complementary foods were calculated for those infants who received breast milk but no other milk feeds. The latest estimated energy requirements from complementary foods, assuming an average breast milk intake, are $200 \mathrm{kcal} \mathrm{day}^{-1}\left(840 \mathrm{~kJ} \mathrm{day}^{-1}\right)$ for infants $6-<9$ months of age, and $300 \mathrm{kcal} \mathrm{day}^{-1}\left(1260 \mathrm{~kJ} \mathrm{day}^{-1}\right)$ for infants $9-<12$ months of age ${ }^{28}$. These recommendations assume good maternal nutritional status and adequate breast milk volume and composition. Data for infants who were breast-feeding at the time of the survey showed that the median and interquartile range (Q1, Q3) for energy intake from complementary foods were 1356 (1040, 1729) kJ for infants aged $6-<9$ months $(n=138)$ and $1625(1295,2030) \mathrm{kJ}$ for infants aged $9-<12$ months $(n=133)$, suggesting an adequate energy intake from complementary foods.

Calculation of the nutrients required from complementary foods is based on the recommended intake for each nutrient minus the amount of the nutrient consumed daily from breast milk. The recommended intakes of micronutrients from complementary foods have been expressed as nutrient densities, by dividing the amounts of nutrients required from complementary foods by the amount of energy needed from complementary foods. The recommended nutrient densities for complementary foods have been updated recently ${ }^{28}$ and are given in Table 4. The amounts of micronutrients per $100 \mathrm{kcal}(420 \mathrm{~kJ})$ from complementary foods were calculated for those infants who received breast milk but no other milk feeds (Table 4), and are expressed as a percentage of the desired density for each nutrient (Fig. 1). The complementary diet did not satisfy micronutrient requirements. Nutrient densities of the complementary foods were less than half the desired density for calcium, iron and zinc for both age categories. Protein density in both age groups was greater than the desired density. 


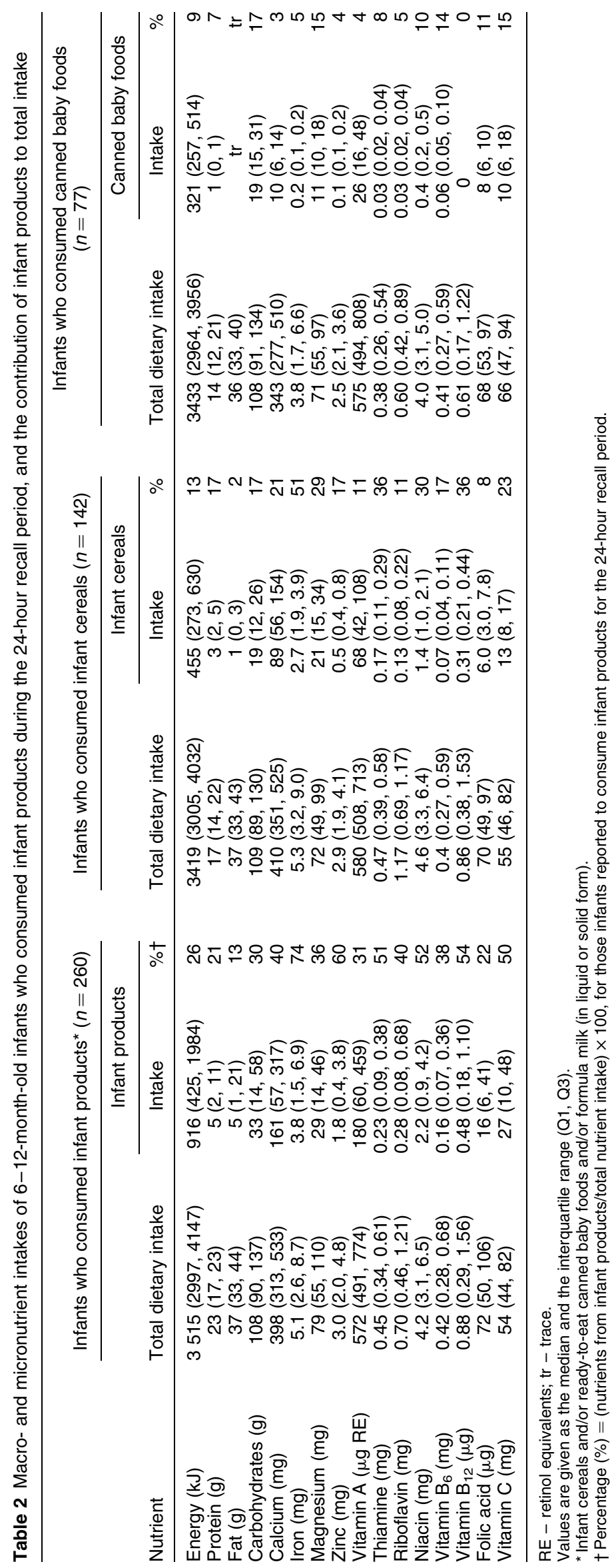


Table 3 Macro- and micronutrient intakes of infants who consumed infant products versus infants who did not consume infant products, for the two age categories separately

\begin{tabular}{|c|c|c|c|c|c|c|}
\hline \multirow[b]{2}{*}{ Nutrient } & \multicolumn{3}{|c|}{$6-<9$ months } & \multicolumn{3}{|c|}{$9-<12$ months } \\
\hline & $\begin{array}{l}\text { Infant products* } \\
\quad(n=140)\end{array}$ & $\begin{array}{c}\text { No infant } \\
\text { products }(n=91)\end{array}$ & $P$-value & $\begin{array}{l}\text { Infant products } \\
\quad(n=120)\end{array}$ & $\begin{array}{l}\text { No infant products } \\
\quad(n=123)\end{array}$ & $P$-value \\
\hline Energy (kJ) & 3398 (2935, 3972) & $3388(3083,3777)$ & 0.9831 & $3665(3105,4502)$ & 3469 (3092, 3924) & 0.0876 \\
\hline Protein $(\mathrm{g})$ & $16(11,16)$ & $14(11,20)$ & 0.0419 & $20(15,28)$ & $17(13,22)$ & 0.0041 \\
\hline Fat $(g)$ & $37(33,42)$ & $40(35,44)$ & 0.0135 & $37(32,45)$ & $39(35,42)$ & 0.5621 \\
\hline Carbohydrates (g) & $105(85,127)$ & $100(69,117)$ & 0.0909 & $114(92,144)$ & $95(83,106)$ & 0.0031 \\
\hline Calcium (mg) & $388(311,519)$ & $273(234,353)$ & 0.0001 & $407(315,587)$ & $259(225,374)$ & 0.0001 \\
\hline Iron (mg) & $4.6(2.2,8.2)$ & $1.0(0.6,2.4)$ & 0.0001 & $5.5(3.2,9.6)$ & $1.5(0.8,2.8)$ & 0.0001 \\
\hline Magnesium (mg) & $76(54,98)$ & $75(52,101)$ & 0.8484 & $89(63,127)$ & $87(66,118)$ & 0.9629 \\
\hline Zinc (mg) & $2.8(1.9,4.0)$ & $2.2(1.7,2.8)$ & 0.0016 & $3.4(2.3,5.2)$ & $2.3(1.8,3.0)$ & 0.0001 \\
\hline Vitamin A ( $\mu \mathrm{g} R E)$ & $573(500,725)$ & $496(465,667)$ & 0.0055 & $555(476,818)$ & $463(423,584)$ & 0.0001 \\
\hline Thiamine (mg) & $0.43(0.31,0.55)$ & $0.27(0.21,0.40)$ & 0.0001 & $0.47(0.37,0.68)$ & $0.32(0.24, .0 .42)$ & 0.0001 \\
\hline Riboflavin (mg) & $0.67(0.45,1.08)$ & $0.40(0.33,0.59)$ & 0.0001 & $0.75(0.49,1.48)$ & $0.39(0.32,0.70)$ & 0.0001 \\
\hline Niacin (mg) & $4.1(3.1,6.2)$ & $2.7(1.9,3.9)$ & 0.0001 & $4.6(3.2,6.9)$ & $2.7(1.9,3.8)$ & 0.0001 \\
\hline Vitamin $B_{6}(\mathrm{mg})$ & $0.39(0.25,0.58)$ & $0.29(0.17,0.48)$ & 0.0041 & $0.47(0.34,0.80)$ & $0.31(0.20,0.53)$ & 0.0001 \\
\hline Vitamin $B_{12}(\mu \mathrm{g})$ & $0.84(0.25,1.41)$ & $0.05(0,0.85)$ & 0.0001 & $1.01(0.40,1.73)$ & $0.04(0,0.80)$ & 0.0001 \\
\hline Folic acid $(\mu \mathrm{g})$ & $64(49,96)$ & $64(51,124)$ & 0.2795 & $88(58,123)$ & $74(49,123)$ & 0.1894 \\
\hline Vitamin C (mg) & $55(44,80)$ & $40(34,48)$ & 0.0001 & $53(41,84)$ & $36(31,55)$ & 0.0001 \\
\hline
\end{tabular}

$\mathrm{RE}$ - retinol equivalents.

Values are given as the median and the interquartile range (Q1, Q3).

* Infant cereals and/or ready-to-eat canned baby foods and/or formula milk (in liquid or solid form).

†Difference between infants consuming infant products and those infants consuming no infant products, Wilcoxon two-sample test.

\section{Foods consumed}

The food items reported for the 24-hour recall period are listed in Table 5 in descending order according to the number of infants for whom the food item was reported. A soft porridge made with maize meal (dry matter content approximately 14\%) was reported for more than half of the infants. It was reported twice for $30 \%$ of the infants and three or more times for $13 \%$ of the infants. Various energyrich food items were usually added to the porridge, namely margarine (66\%), peanut putter (42\%), sugar (41\%), formula milk powder (23\%) and eggs (5\%). On average, one $(36 \%)$, two $(33 \%)$, three $(23 \%)$ or four or more (4\%) of these food items were added simultaneously to the porridge. Only $4 \%$ of the infants had nothing added to their porridge. Infant cereals were reported for 31\% and ready-to-eat canned baby foods for $17 \%$ of the infants.

The percentage of infants who consumed animal foods, dairy products and vitamin-A-rich fruit and vegetables during the 24-hour recall period is given in Table 6. Fewer than $20 \%$ of the infants consumed foods of animal sources on the day of recall. Dairy products were reported for $26 \%$ of the infants, but there was a sharp decrease with age: $36 \%$ in the 6-<9-month age category versus $18 \%$ in the 9$<12$-month age category. Eighteen per cent of the infants consumed vitamin-A-rich fruit and vegetables, pumpkin and butternut mostly, during the 24-hour recall period.

Table 4 Protein and micronutrients, and nutrient densities, of complementary foods alone for infants aged $6-<9$ months and $9-<12$ months for whom breast milk was the only milk feed

\begin{tabular}{|c|c|c|c|c|c|c|}
\hline & \multicolumn{2}{|c|}{ Nutrient } & \multicolumn{4}{|c|}{ Nutrient per $100 \mathrm{kcal}$} \\
\hline & \multirow{2}{*}{$\begin{array}{c}\begin{array}{c}6-<9 \text { months } \\
(n=138)\end{array} \\
\text { Intake }\end{array}$} & \multirow{2}{*}{$\frac{\begin{array}{c}9-<12 \text { months } \\
(n=133)\end{array}}{\text { Intake }}$} & \multicolumn{2}{|c|}{$\begin{array}{c}6-<9 \text { months } \\
(n=138)\end{array}$} & \multicolumn{2}{|c|}{$\begin{array}{c}9-<12 \text { months } \\
(n=133)\end{array}$} \\
\hline & & & Desired $^{*}$ & Intake & Desired* $^{*}$ & Intake \\
\hline Protein (g) & $15(12,18)$ & $17(14,21)$ & 1.0 & $2.37(1.87,3.14)$ & 1.0 & $2.45(1.86,3.20)$ \\
\hline Calcium (mg) & $83(29,166)$ & $78(34,192)$ & 105 & $22(11,44)$ & 74 & $19(9,44)$ \\
\hline Iron (mg) & $1.6(0.7,3.2)$ & $1.7(1.1,2.8)$ & 4.5 & $0.5(0.2,0.8)$ & 3.0 & $0.7(0.4,0.7)$ \\
\hline Magnesium (mg) & $48(27,70)$ & $60(40,82)$ & 15 & $15(11,18)$ & 11 & $15(12,18)$ \\
\hline Zinc (mg) & $0.9(0.5,1.4)$ & $1.2(0.7,1.8)$ & 1.6 & $0.3(0.2,0.4)$ & 1.1 & $0.3(0.2,0.4)$ \\
\hline Vitamin A ( $\mu \mathrm{g} R E)$ & $93(38,210)$ & $92(43,187)$ & 31 & $29(12,65)$ & 30 & $28(13,58)$ \\
\hline Thiamine (mg) & $0.24(0.14,0.35)$ & $0.26(0.19,0.36)$ & 0.08 & $0.07(0.05,0.08)$ & 0.07 & $0.06(0.05,0.08)$ \\
\hline Riboflavin (mg) & $0.18(0.07,0.34)$ & $0.16(0.07,0.34)$ & 0.08 & $0.05(0.02,0.10)$ & 0.06 & $0.04(0.02,0.08)$ \\
\hline Niacin (mg) & $1.7(0.8,2.7)$ & $1.9(1.1,2.8)$ & 1.5 & $0.5(0.3,0.8)$ & 1.0 & $0.5(0.3,0.6)$ \\
\hline Vitamin $B_{6}(\mathrm{mg})$ & $0.20(0.11,0.76)$ & $0.23(0.14,0.35)$ & 0.12 & $0.06(0.04,0.08)$ & 0.08 & $0.06(0.04,0.08)$ \\
\hline Vitamin $B_{12}(\mu \mathrm{g})$ & $0.18(0,0.61)$ & $0.09(0,0.60)$ & 0.08 & $0.06(0,0.19)$ & 0.03 & $0.01(0,0.14)$ \\
\hline Folic acid $(\mu \mathrm{g})$ & $26(14,60)$ & $45(19,82)$ & 11 & $7(5,17)$ & 9 & $10(6,19)$ \\
\hline Vitamin C (mg) & $12(3,24)$ & $10(3,29)$ & 1.5 & $3.5(1.1,8.8)$ & 1.7 & $3.0(0.8,8.9)$ \\
\hline
\end{tabular}

$\mathrm{RE}$ - retinol equivalents.

Values are given as the median and interquartile range (Q1, Q3).

* World Health Organization 2002 guidelines for nutrient density were used ${ }^{28}$ 


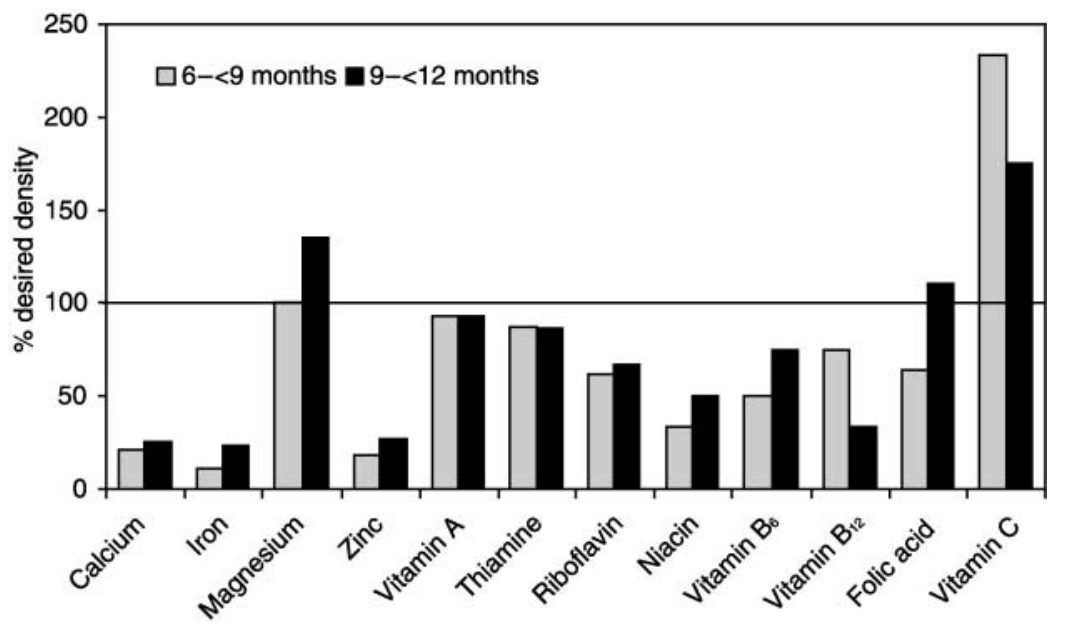

Fig. 1 Nutrient densities of complementary foods expressed as a percentage of the desired nutrient density per age category

\section{Discussion}

Energy intake and protein density from complementary foods were adequate, but nutrient density was inadequate for several of the micronutrients, especially calcium, iron and zinc. This indicates that the nutritional composition rather than the amount consumed is the key aspect of complementary foods that needs to be improved.

Maize meal was an integral part of the diet as $82 \%$ of the 6-12-month-old infants consumed a soft porridge made

Table 5 Foods consumed by $5 \%$ or more of the infants during the 24 -hour recall period

\begin{tabular}{|c|c|c|c|c|c|c|}
\hline \multirow[b]{2}{*}{ Food item } & \multicolumn{2}{|c|}{$\begin{array}{l}\text { Infants } \\
(n=475)\end{array}$} & \multirow[b]{2}{*}{ Frequency } & \multicolumn{3}{|c|}{ Portion size (g) } \\
\hline & $n$ & $\%$ & & Average & Minimum & Maximum \\
\hline Soft porridge made with maize meal & 391 & 82 & 639 & 115 & 10 & 300 \\
\hline Breast milk & 369 & 78 & - & - & - & - \\
\hline Rice & 180 & 38 & 214 & 45 & 10 & 160 \\
\hline Formula milk* & 158 & 33 & 556 & 20 & 2 & 60 \\
\hline Infant cereals† & 142 & 31 & 224 & 20 & 5 & 50 \\
\hline Legumes & 116 & 24 & 132 & 50 & 15 & 175 \\
\hline Peanut butter & 106 & 22 & 135 & 5 & 2 & 20 \\
\hline Potato & 101 & 21 & 115 & 80 & 10 & 200 \\
\hline Stiff porridge made with maize meal ( $p h u t u$ ) & 82 & 17 & 85 & 90 & 20 & 240 \\
\hline Ready-to-eat canned baby foods $\ddagger$ & 79 & 17 & 97 & 135 & 40 & 250 \\
\hline Pumpkin, butternut squash & 65 & 14 & 67 & 80 & 15 & 200 \\
\hline Orange & 59 & 12 & 59 & 115 & 40 & 190 \\
\hline Banana & 45 & 9 & 45 & 60 & 25 & 100 \\
\hline Yoghurt & 44 & 9 & 47 & 130 & 80 & 175 \\
\hline Milk powder & 43 & 9 & 127 & 20 & 2 & 50 \\
\hline Savoury snacks & 42 & 9 & 42 & 45 & 10 & 160 \\
\hline Eggs§ & 40 & 8 & 41 & 55 & 45 & 100 \\
\hline Bread & 39 & 8 & 45 & 40 & 25 & 60 \\
\hline Curry sauce & 32 & 7 & 36 & 25 & 10 & 50 \\
\hline Fresh milk* & 31 & 6 & 47 & 75 & 15 & 250 \\
\hline Chicken & 28 & 6 & 30 & 30 & 20 & 55 \\
\hline Soup & 24 & 5 & 26 & 50 & 10 & 100 \\
\hline Imifinol| & 24 & 5 & 24 & 50 & 25 & 80 \\
\hline
\end{tabular}

Foods consumed by less than $5 \%$ of the infants: $4 \%$ of infants - orange juice, morvite porridge; $3 \%$ of infants - cabbage, fermented milk, beef, tea, cordials; $2 \%$ of infants - samp-and-beans, pear, custard, tomato-and-onions, cooked apple, biscuits, mixed vegetables, apple, infant juice; $1 \%$ of infants - fish, spinach, breakfast cereal; $<1 \%$ of infants - maltabella porridge, chips, sweet potato, popcorn, sweets, sardine, mealie, gem squash, jam, mango, pawpaw, peach, plum, avocado, milk shake, liver, sausage, carbonated drinks, chocolate.

Water, sugar and fats (e.g. margarine, oil and holsum) are not listed. For bottle feeds, water and formula powder were coded separately. Sugar and fats were often added to foods and were not coded separately.

* Either as a bottle feed or mixed into the porridge.

†'Just-add-water' type (16\%), 'just-add-milk' type (15\%).

f Fruit $(13 \%)$, vegetables $(3 \%)$, yoghurt $(<1 \%)$, custard $(<1 \%)$.

$\S$ Boiled, fried, scrambled or mixed into the porridge.

I Brown bread $(6 \%)$, white bread $(2 \%)$.

II Imifino is a collection of various dark-green leaves that is eaten as a vegetable, the leaves either grow wild or come from vegetables such as pumpkin and beetroot. 
Table 6 Percentage of 6-12-month-old infants who consumed animal products, dairy products and vitamin-A-rich fruit and vegetables during the 24-hour recall period

\begin{tabular}{lccc}
\hline Food group & $\begin{array}{c}\text { All } \\
(n=475)\end{array}$ & $\begin{array}{c}6-<9 \text { months } \\
(n=224)\end{array}$ & $\begin{array}{c}9-<12 \text { months } \\
(n=243)\end{array}$ \\
\hline Animal products (\%) & 17 & 12 & 23 \\
Dairy products (\%) & 26 & 36 & 18 \\
Vitamin-A-rich fruits & 18 & 16 & 19 \\
$\quad$ or vegetables (\%) & & & \\
\hline
\end{tabular}

with maize meal during the 24-hour recall period; $43 \%$ of the infants consumed it at least twice per day. It is unlikely that fortification of staple foods such as maize meal will impact significantly on infant feeding because of the small amounts that infants consume. On average, a soft porridge made with maize meal provides $51 \mathrm{kcal}$ per $100 \mathrm{~g}^{20}$, which is lower than the minimum desired energy density of $0.8 \mathrm{kcal} \mathrm{g}^{-1}$ for complementary foods for infants receiving at least three meals per day ${ }^{28}$. However, various energyrich foods (e.g. sugar, margarine and peanut butter) were added to the porridge of most of the infants, thereby increasing the energy density.

The nutrient density required of complementary foods is high because of the small amounts that are consumed by infants. The calculation of desired nutrient densities of complementary diets is complicated because no single set of nutritional requirements for infants has been agreed upon; some micronutrients (e.g. some of the B vitamins, vitamin $\mathrm{A}$, iodine and selenium) are highly variable in human milk, depending on the woman's nutritional status; and the intake of human milk is highly variable ${ }^{29}$. Given these limitations, the estimated desired nutrient densities serve as a guide only.

The nutrient density of the complementary diet was low. Calcium, iron and zinc were identified as the major problem nutrients, with nutrient densities less than half of that desired. The low iron intake in this age category is of concern. An insufficient iron intake will result in the depletion of iron stores and eventually iron-deficiency anaemia (60\% of the study population had depleted iron stores and $49 \%$ presented with low Hb concentrations unpublished data). Children with low $\mathrm{Hb}$ concentrations during infancy are at risk of being adversely affected in terms of developmental outcomes ${ }^{30}$.

It is difficult to satisfy iron requirements of infants in the absence of fortified foods ${ }^{29}$ and the World Health Organization has recognised that fortification of complementary foods is a possible strategy for addressing iron deficiency in this age group ${ }^{31}$. Thirty-one per cent of the infants consumed fortified infant cereals on the day of recall. The infant cereal used mostly contained $15 \mathrm{mg}$ iron per $100 \mathrm{~g}$ dry product ${ }^{20}$, which is much lower than a recent proposal of $27.5 \mathrm{mg}$ ( $11 \mathrm{mg}$ iron per $40 \mathrm{~g}$ daily portion $)^{32}$. A significant reduction in the prevalence of low $\mathrm{Hb}$ concentrations was observed after infants consumed a specially formulated porridge that supplied $11 \mathrm{mg}$ iron per day for six consecutive months (unpublished data). Increasing the levels of iron fortification in currently available fortified infant cereals should therefore be considered.

The average portion size for infant cereals was $20 \mathrm{~g}$, which is lower than the recommended portion size of $30 \mathrm{~g}$ for the 'just add milk' type cereals and $50 \mathrm{~g}$ for the 'just add water' type cereals as indicated on the packaging. Inadequate intake of infant cereals has been reported in other studies in South Africa $^{14,15}$. The cost of these products probably prohibits an adequate intake. To reach those infants that are most vulnerable in terms of malnutrition, it is important that fortified infant products are affordable to the majority of the population.

Ready-to-eat canned baby foods were consumed by $17 \%$ of the infants on the day of recall, and for these infants ready-to-eat canned baby foods contributed less than 15\% of total intake for all the micronutrients. It is questionable whether the cost of these products justifies their use in the lower socio-economic sector, as their contribution towards total nutrient intake is small. Mothers should be encouraged to use home-prepared food instead of ready-to-use canned food (e.g. home-prepared vegetables instead of ready-to-use canned vegetables), as this will save money without compromising nutrients.

Dewey and Brown stated that intakes of certain (but not all) micronutrients could be increased by improving the nutritional quality of home-prepared complementary foods ${ }^{28}$. For example, vitamin A intake could potentially be increased by regular consumption of $\beta$-carotene-rich fruit and vegetables (only 18\% of the infants consumed $\beta$-carotene-rich fruit and vegetables on the day of recall). The local production of these vegetables could be promoted through existing programmes, such as the Social Plant Use Programme of The Valley Trust in the study area. Higher intakes of foods from animal sources are usually associated with greater nutrient intakes and dietary quality, and it is therefore recommended that meat, poultry, fish or eggs should be eaten daily, or as often as possible ${ }^{33}$. However, these foods are expensive and regular consumption in the lower socio-economic sector is probably unlikely. The low intake of foods of animal sources and dairy products contributed towards the low nutrient density of the complementary diet for iron, zinc and calcium.

In non-famine situations, dietary quality and feeding practices are likely to be more important than energy intake in the aetiology of child malnutrition ${ }^{34}$. Data from Guatemala showed that a greater intake of energy and nutrients is not necessarily associated with greater nutrient density $^{35}$. In our study, energy intake from the complementary diet was $62 \%$ higher than the proposed recommendation on which the calculation of nutrient densities is based. Infants who consumed infant products had significantly higher intakes for most of the micronutrients than infants who did not consume any infant 
products. Infant products therefore have a role in infant feeding. It is important that the levels of fortification are optimal and that these products are affordable to the majority of the population to ensure adequate intake. It is acknowledged that infant products should be used in a broader strategy to improve infant nutrition.

In conclusion, the nutrient composition of the complementary diet was inadequate, especially for iron, zinc and calcium. Infants who consumed infant products had higher micronutrient intakes than infants who did not consume infant products. The nutrition composition of home-prepared complementary meals should be improved, the levels of fortification of currently available fortified infant cereals should be revised (especially for iron), and the industry should be committed to produce fortified infant products that are more affordable.

\section{Acknowledgements}

The South African Sugar Association funded the study. It was part of the baseline survey of a randomised controlled trial funded by Thrasher Research Fund and done in collaboration with The Valley Trust through their Community-based Health Program. I extend my sincere appreciation to the staff of The Valley Trust, especially Bongi Mtshali; the team of nutrition monitors, Derick Mkhize, Nhlanhla Hlophe, Lindiwe Msiya, Eunice Mhlongo and France Phungula; the community health workers and their facilitators; Jennifer Gamlin who captured the data; Banu Adams who coded the 24-hour dietary recall data, and the mothers and children who participated in the study.

\section{References}

1 World Health Organization (WHO). Infant and Young Child Nutrition. Technical Consultation on Infant and Young Child Feeding, A53/INF.DOC/2. Geneva: WHO, 2000.

2 Black RE, Morris SS, Bryce J. Where and why are 10 million children dying every year? Lancet 2003; 361: 2226-34.

3 World Health Organization (WHO). Nutrition for Health and Development. A Global Agenda for Combating Malnutrition. WHO/NHD/00.6. Geneva: WHO, 2000.

4 World Health Organization (WHO)/United Nations Children's Fund. Global Strategy for Infant and Young Child Feeding. Geneva: WHO, 2003.

5 South African Vitamin A Consultative Group (SAVACG). Anthropometric, vitamin A, iron and immunisation coverage status in children aged 6-71 months in South Africa, 1994. South African Medical Journal 1996; 86: 354-7.

6 Gibson RS, Ferguson EL, Lehrfeld J. Complementary foods for infant feeding in developing countries: their nutrient adequacy and improvement. European Journal of Clinical Nutrition 1998; 52: 764-70.

7 Lartey A, Manu A, Brown KH, Peerson JM, Dewey KG. A randomized, community-based trial of the effects of improved, centrally processed complementary foods on growth and micronutrient status of Ghanaian infants from 6 to 12 mo of age. American Journal of Clinical Nutrition 1999; 70: 391-404.

8 Bentley ME, Dickin KL, Mebrahtu S, Kayode B, Oni GA, Verzosa CC, et al. Development of a nutritionally adequate and culturally appropriate weaning food in Kwara State, Nigeria: an interdisciplinary approach. Social Science $\mathcal{E}$ Medicine 1991; 33: 1103-11.

9 Huffman SL, Oniang'o R, Quinn V. Improving young child feeding with processed complementary cereals and behavioural change in urban Kenya. Food and Nutrition Bulletin 2000; 21 : 75-81.

10 Faber M, Oelofse A, Kriek JA, Benadé AJS. Breastfeeding and complementary feeding practices in a low socio-economic urban and a low socio-economic rural area. South African Journal of Food Science and Nutrition 1997; 9: 43-51.

11 Skinner JD, Carruth BR, Houck KS, Coletta F, Cotter R, Ott D, et al. Longitudinal study of nutrient and food intakes of infants aged 2 to 24 months. Journal of the American Dietetic Association 1997; 97: 496-504.

12 Devaney B, Ziegler P, Pac S, Karwe V, Barr SI. Nutrient intakes of infants and toddlers. Journal of the American Dietetic Association 2004; 104(Suppl. 1): S14-S21.

13 Fox MK, Pac S, Devaney B, Jankowski L. Feeding Infants and Toddlers Study: what foods are infants and toddlers eating? Journal of the American Dietetic Association 2004; 104(Suppl.1): S22-30.

14 Oelofse A, van Raaij JMA, Benadé AJS, Dhansay MA, Tolboom JJM, Hautvast JGAL. Disadvantaged black and coloured infants in two urban communities in the Western Cape, South Africa differ in micronutrient status. Public Health Nutrition 2002; 5: 289-94.

15 Faber M, Benadé AJS. Perceptions of infant cereals and dietary intakes of children aged 4-24 months in a rural South African community. International Journal of Food Science and Nutrition 2001; 52: 359-65.

16 Smuts CM, Faber M, Dhansay MA, Benadé AJS. International Research of Infant Supplementation (IRIS). Multi-centre Study of the Efficacy of Multi-micronutrient Supplementation in Small Children. Tygerberg: Medical Research Council, 2002.

17 Faber M, Kvalsvig JD, Lombard CJ, Benadé AJS. The Effect of a Low-cost Micronutrient Fortified Cereal on the Nutritional Status of Infants. Tygerberg: Medical Research Council, 2004

18 Langenhoven ML, Conradie PJ, Wolmarans P, Faber M. MRC Food Quantities Manual, 1991, 2nd ed. Parow: Medical Research Council, 1991.

19 World Health Organization (WHO). Complementary Feeding of Young Children in Developing Countries. A Review of Current Scientific Knowledge. WHO/NUT/98.1. Geneva: WHO, 1998.

20 Langenhoven ML, Kruger M, Gouws E, Faber M. MRC Food Composition Tables, 1991, 3rd ed. Parow: Medical Research Council, 1991.

21 National Academy of Sciences. Dietary Reference Intakes for Energy, Carbohydrate, Fiber, Fat, Fatty Acids, Cholesterol, Protein, and Amino Acids (Macronutrients), 2003. Available at http://books.nap.edu/catalog/10490.html

22 National Academy of Sciences. Dietary Reference Intakes for Calcium, Phosphorous, Magnesium, Vitamin D, and Fluoride, 2003. Available at http://books.nap.edu/catalog/ 5776.html

23 National Academy of Sciences. Dietary Reference Intakes for Thiamin, Riboflavin, Niacin, Vitamin $B_{6}$, Folate, Vitamin $B_{12}$, Panthothenic Acid, Biotin, and Choline, 2003. Available at http://books.nap.edu/catalog/6015.html

24 National Academy of Sciences. Dietary Reference Intakes for Vitamin A, Vitamin K, Arsenic, Boron, Chromium, Copper, Iodine, Iron, Manganese, Molybdenum, Nickel, Silicon, Vanadium, and Zinc, 2003. Available at http://books.nap. edu/catalog/10026.html

25 National Academy of Sciences. Dietary Reference Intakes for Vitamin C, Vitamin E, Selenium, and Carotenoids, 2003. Available at http://books.nap.edu/catalog/9810.html 
26 National Academy of Sciences. Dietary Reference Intakes: Applications for Dietary Assessment, 2003. Available at http://books.nap.edu/catalog/9956.html

27 Lanigan JA, Wells JC, Lawson MS, Cole TJ, Lucas A. Number of days needed to access energy and nutrient intake in infants and young children between 6 and 12 months of age. European Journal of Clinical Nutrition 2004; 58: 745-50.

28 Dewey KG, Brown KH. Update on technical issues concerning complementary feeding of young children in developing countries and implications for intervention programs. Food and Nutrition Bulletin 2003; 24: 5-28.

29 Lutter CK, Rivera JA. Nutritional status of infants and young children and characteristics of their diets. Journal of Nutrition 2003; 133: 2941S-9S.

30 Lozoff B, Jimenez E, Wolf AW. Long-term developmental outcome of infants with iron deficiency. New England Journal of Medicine 1991; 325: 687-94.

31 World Health Organization (WHO). Iron Deficiency
Anaemia: Assessment, Prevention and Control. A Guide for Programme Managers. WHO/NHD/01.3. Geneva: WHO, 2001.

32 Lutter CK, Dewey KG. Proposed nutrient composition for fortified complementary foods. Journal of Nutrition 2003; 133: 3011S-20S.

33 Pan American Health Organization (PAHO)/World Health Organization. Guiding Principles for Complementary Feeding of the Breastfed Child. Washington, DC: PAHO, 2003.

34 Lutter C. Meeting the challenge to improve complementary feeding. SCN News 2003; 27: 4-9.

35 Brown KH, Peerson JM, Kimmons JE, Hotz C. Options for achieving adequate intake from home-prepared complementary foods in low income countries. In: Black RE, Fleisher Michaelsen K, eds. Public Health Issues in Infant and Child Nutrition. Philadelphia, PA: Nestec Ltd/Lippincott Williams and Wilkins, 2002. 